\title{
Religious Affiliations and Organizational Citizenship Behaviour in Institutions of Higher Learning in Rivers State
}

\author{
Korsi Gbarale \\ Department of Management, Faculty of Management Sciences, Rivers State University of Science and \\ Technology
}

\begin{abstract}
This study investigated the relationship between religious affiliations and organizational citizenship behaviour. The study utilizes the descriptive and inferential statistical methods in the assessment of data generated using structured questionnaire instruments from a total of 236 academic and non-academic staff of three Universities and a Polytechnic within the State. The study is designed as a cross-sectional survey and data is primarily quantitative. A total of two null hypotheses were tested using the Spearman's rank order correlation coefficient with results indicating that there is a significant association between religious affiliation and the dimensions of organizational citizenship behaviour (altruism and sportsmanship). The findings of the study indicate substantial reference to the presence of religious affiliations as a significant antecedent of organizational citizenship behaviour within the selected Universities and Polytechnic of the State.
\end{abstract}

Keywords: Religious affiliations, altruism, sportsmanship, organizational citizenship behaviour

\section{Introduction}

An organization usually comes into existence when explicit procedures are established to co-ordinate the activities of a group in the interest of achieving specific objectives. Hunt (1972) described an organization as an identifiable social entity pursuing multiple objectives through the coordinated activities and relations among members in the organization. It is true that whenever groups of people associate with one another; social organization develops among them, but not all such collectivities can be referred to as formal organizations. The criteria for describing a formal organization is the existence of a procedure for mobilizing and coordinating the efforts of various individuals and groups in the pursuit of joint objectives which has been institutionalized by either management or government. Over the years, the study of groups at workplace has emerged as an increasingly important part of the organizational behavior and management literature. This is more so, since it is an accepted fact that group affiliation is part of most employee's work life. More importantly, it is also believed that groups can restrict or enhance the accomplishment of organizational goals. African studies in organization behavior $(\boldsymbol{O B})$ have hitherto focused on the functioning of formal groups to the neglect of informal groups (Appelbaum et al 2004; Ejiofor, 1981; Ahiauzu, 1983). This situation has tended to create a gap within the process of effective management of Institutions of Higher Learning. This situation shows that full scale knowledge on the effectiveness of Institutions of Higher Learning is at present inadequate.

We are aware that research evidence on formal group dynamics have shown that the working people of the economically advanced countries are individualistic in nature whereas those in the less developed countries are collectivistic. In explaining the concept of individualism and collectivitism, Erturk (2006) posited that individualism stands for a preference for a loosely knit social framework in a society wherein individuals are supposed to take care of themselves and their immediate families only: Whereas collectivism stands for a preference for a tightly knit social framework in which individuals can expect their relatives, clan and other Ingroups to look after them in exchange for unquestioning loyalty. It is therefore not surprising that in individualistic societies workers tend not to rely too much on the support of the group in performing their functions within work organizations. This is not to say the least that group support in individualistic societies is unimportant. Unlike the individualistic society therefore, collectivistic societies such as in Nigerian society inculcate in their members the need to act in groups. In the wider African societies, these groups have tended to emerge more from social relations rather than from economic rational relations. Studies have tended to focus on the more favoured economic rational formal groups to the neglect of the importance of informal groups in determining the performance patterns of formal work organization. Hence this paper contributes by empirically examining the effect of religious affiliations on organizational citizenship behaviour in three Universities and a Polytechnic in Port Harcourt. The study therefore is aimed at:

i. Ascertaining the relationship between religious affiliations and altruism

ii. Examining the relationship between religious affiliations and sportsmanship 


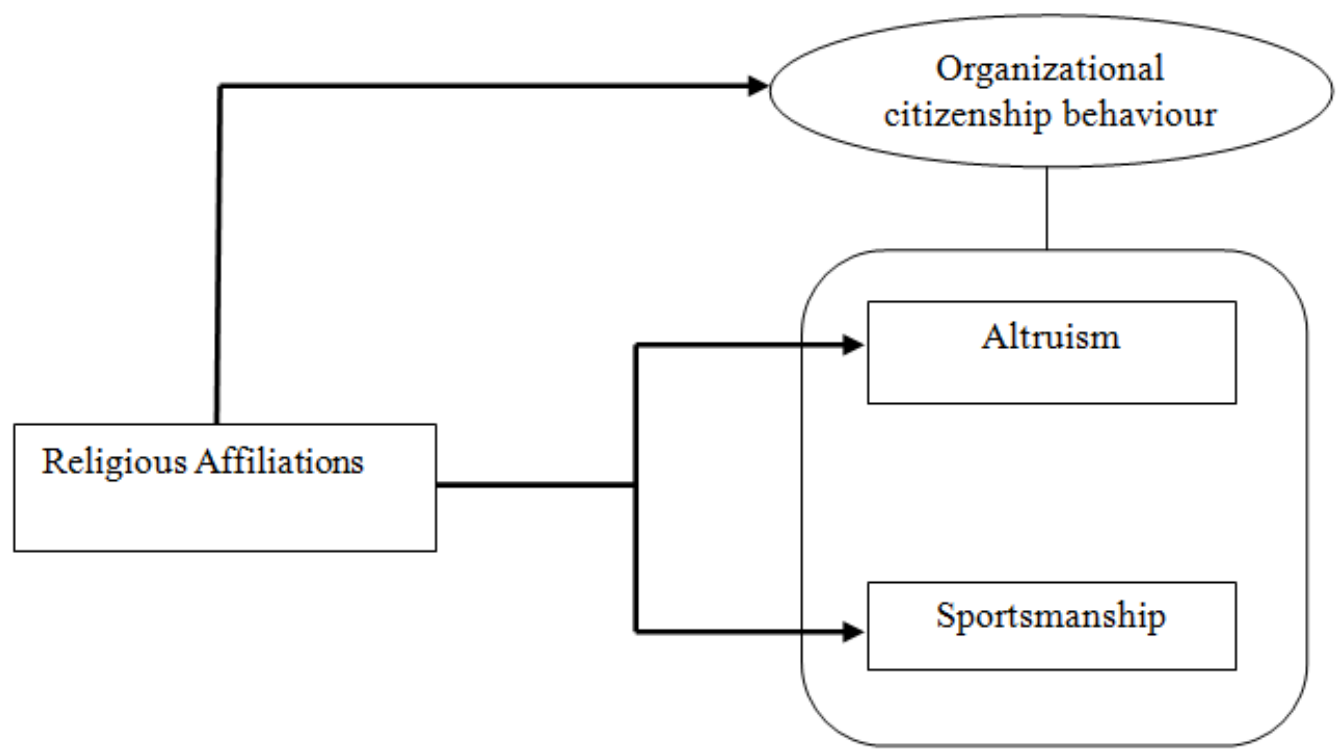

Figure 1: Conceptual Framework for the study of Religious Affiliations and Organizational Citizenship Behaviour in Institutions of Higher Learning

\subsection{Religious Affiliations}

\section{Literature Review}

According to Horton and Hunt (1984) religious institutions are a society's important systems of religious beliefs and practices which are standardized and formulated and which are widely shared and viewed as necessary truism. Although, there are many definitions of religion as a system of beliefs and practices by which a group of people interpret and respond to what they feel is supernatural and sacred. It is also believed that all societies believe in supernatural beings, some kind of supernatural life, having effect on their living. Religious institution, like other institutions, is a means, an instrument for the satisfaction of needs. As a belief system, it may be highly charged emotionally. Horton and Hunt (1984) pointed out that in Singapore, the government has faith on the effect of religious instruction in their schools and all major religions stress such basic virtues as honesty and consideration for others. These are observed to be necessary for the orderly conduct of human society.

Otite and Ogionwo (1979) argued that sociologists are interested in the study of religion not merely because of its central theoretical problem but also of the importance of its relationship to other areas of social life and the roles, movement, and organization strategies associated with it. Apart from producing moral behavior, religion provides answers for puzzling questions. Some have also seen religion mainly in its solidarity and integration aspects. In this sense, religion contributes to order in society by creating for social well-being, self discipline, social cohesion and continuity of culture and traditions. Because of its influence on its members (people), religion can serve to maintain structural stability of discouraging rebellion and opposition in the existing socio-economic order.

The role of religion is seen as providing an organized picture of the universe and under this condition man defines his identity and his environment and relates more consciously, confidently and orderly to the supernatural. Also those who belong to one religion, be it Buddhism, Christianity, Islam just to mention a few, carry appropriate feelings of loyalty and identity in a unified system of beliefs and practices. The importance of religion can be ascertained from its ability to mobilize members and maintain the internal structures of the society concerned.

Reporting the works of Vittorio Lanternari, Otite and Ogionwo (1979) described religion as an instrument for fighting oppression and persecution. Reacting to the colonial situations in Angola, Zaire Congo Brazzaville, Kenya, Tanzania, to mention but a few, Africans who were subjected to misery and persecution sought relief from their frustration and sufferings in religious ways. Durkheim (1912) found from his studies of religious practices of Australian aborigines and South Seas Islanders that the main purpose of religion in primitive societies was to help people make contact not with God but with one another. The author in his findings also observed that religious rituals helped people to develop a sense of community as they shared the experiences of marriage, birth, and death and celebrated the planting and harvest seasons and the winter. This united the group leaving none to face life alone.

Where different faiths and denominations exist, religion may not easily unite the entire society, but it can unite each religious group in a mutual support system. Weber (1964) described religion as a dynamic force 
after examining the rise of capitalism; felt that it was favoured by the attitudes stressed by ascetic Protestantism. Therefore, rather than religion being without real influence, it actually helps to formulate the direction of economic change.

Religion is said to have an impact on social action. For instance, the conservatives hold that religion should promote personal salvation, help develop the spirit of love, unselfishness and faith which can survive social difficulties. Therefore, they may be willing to make minor adjustment, but they are convinced that the basic structures of society are sound. They may accept and even support 'reform', but revolution is rejected as likely to bring more harm than benefits. Religion has the tendency of influencing social stratification. For instance, in United States of America, there are many religious bodies each linked to a certain segment of society. In this way many people reaffirm their identity by affiliating with a religious body composed primarily of people from his area. Religious stratification sometimes is based on ethnicity. For instance, Judaism is a religion in which most worshippers are ethnically Jewish. Even though there is the concept of Jewishness without also thinking of the Jewish religion.

\subsection{Nature and Measures of Organizational Citizenship Behaviour}

Individual level performance draws upon those things you have to do in your job, or in-role performance. These things are those things one has to do as part of his job and its job description, and those things that add value but which are not part of one's formal job description. These "extras" are called extra role performance or organization citizenship behaviour (OCBs) Voluntary behaviour employees perform to help others and benefit the organization. At this point, it is probably simplest to consider an in role performance as having productivity and quality dimensions associated with certain standards that you must meet to do your job. In contrast, $\boldsymbol{O C B \boldsymbol { s }}$ can be understood as behaviour that are beneficial to the organization and are discretionary, not directly or explicitly recognized by the formal reward system.

A group: a collection of individuals who interact with each other such that one person's actions have an impact on the other informal groups. Group level performance focuses on both the outcomes and process of collections of individuals, or groups. Individual can work their own agendas in the context of the group. Group might consist of project-related groups, such as a product or an entire store or branch of company. The performance of a group consists of the input of the group minus any process loss that result in the final output, such as the quality of product and the ramp-up time to production or the sales for a given month. Process loss any aspect of group interaction that inhibits group functioning is any aspect of group interaction that inhibits good problem solving (Chao-Chan, 2011; Kpakol, Obiora \& Jaja, 2016). In comparison to in-role performance, the spectrum of what constitutes extra-role performance, or $\boldsymbol{O C B S}$, seem to be great and growing. In a recent review, for example, management researchers identified 30 potentially different forms $\boldsymbol{O C} \boldsymbol{B}$, which they conveniently collapsed into seven common dimensions: (1) helping behaviour, (2) sportsmanship, (3) organizational loyalty, (4) organizational compliance (5) individual initiative, (6) Civic Virtue and (7) self-development.

\subsection{Religious Affiliations and Organizational Citizenship Behaviour}

2.3.1 Religious affiliations and altruism: Altruism refers to voluntary actions that help other people with a work problem, instructing a new hire on how to use equipment, helping a co-worker catch up with a backlog of work, fetching materials that a colleague needs and cannot produce on their own. Interpersonal helping focuses on helping co-workers in their jobs when such help was needed. This helping behaviour takes on the forms of altruism, interpersonal courtesy, and peacemaking and cheerleading. It is the position of various studies () that religious affiliations, are bonding mechanisms and would most likely contribute or enhance outcomes of altruism in members of the organization, based on these assumptions, we hypothesize that:

$\mathrm{HO}_{1}$ : There is no significant relationship between religious affiliations and altruism

2.3.2 Religious affiliations and sportsmanship: Sportsmanship is a citizen like posture of tolerating the inevitable inconveniences and impositions of work without whining and grievances. It is the Identification with and allegiance to organizational leaders and the organization as a whole, transcending the parochial. It extends to organizational loyalty which has to do with interests of individual's workgroups, and departments. It is a form of representative behaviour which includes defending the organization against threats, contributing to it good reputation, and co-operating with others to serve the interests of the whole. It can be summed up as organizational compliance or obedience which is an orientation toward organizational structure of rules and regulations. Obedience may be demonstrated by a respect for rules and instructions, punctuality in attendance and task completion, and stewardship of organizational resources. Therefore based on these assertions we hypothesize that:

$\mathrm{HO}_{2}$ : There is no significant relationship between religious affiliations and sportsmanship 


\subsection{Research Design}

\section{Methodology}

The study adopts the cross-sectional survey research design which allows the researcher to have a snapshot of the phenomenon investigated at a time. The design also allows the use of the structured questionnaire for data generation and analysis. Data for the study is predominantly quantitative and thus emphasis is placed on the use of descriptive and inferential statistics in the analysis of data.

\subsection{Population and Sampling}

The population of study is comprised of a total of 3136 academic and non- academic staff in the three universities and polytechnic in Port Harcourt (Nigerian muse, 2005) from where the sample size of 355 for the study was determined, using the Taro Yamane 1973 sampling formula (Okpu \& Kpakol, 2015). Respondents were selected using the simple random probabilistic sampling method.

\subsection{Research Instrument}

This research adopted the questionnaire as its primary instrument for data generation. It is a formalized schedule which directs the questioning process and promotes clear and proper recording (Ezejelue and Ogwo, 1990). It was administered by direct contact to ensure objective participation that in turn generates realistic inferences. The questions were presented in close ended forms.

\subsection{Operational Measurement of Variables}

The research instrument used for the study is the questionnaire which was adopted from the works of Lind and Tyler (2008) as adopted by Bies (2011), Organ (1988) and Child (1972). The instruments elicited information on Religious affiliations and the dimensions of Organizational Citizenship Behaviour.

The questionnaire will consist of three sections (A, B and C). Section $\boldsymbol{A}$ focused on the personal data of the respondents such as sex, age, marital status, educational qualification, and years of working experience. Section $\boldsymbol{B}$ of the questionnaire focused on Religious Affiliations which is considered the predictor variable in this study, while Section $\boldsymbol{C}$, measured the measures of Organizational Citizenship Behaviour. The Questionnaire will be designed in a 1 to 4 point level of Modified Likert Scale Measurement.

\subsection{Reliability of Instrument}

The reliability of the instrument was determined by the use of Nunally's (1978) Cronbach's alpha. Variables were observed to exceed the benchmark of 0.7 minimum threshold. Cronbach's alpha is a reliability coefficient that indicates how well the items in a set are consistent with respect to their latent constructs.

\section{Data Presentation, Analysis and Interpretation}

This section presents the results for the analyzed data generated from our field exercise. The results and findings were also summarized here. This had commenced with the result on the administration and retrieval of questionnaire copies.

\subsection{Descriptive Analysis}

The survey instrument was distributed among sample respondents in the four higher educational institutions in the state. A total of 355 of them were served and 245 of them were successfully retrieved. The eventual sorting and cleaning provide 236 of the survey instrument as good for the study.

Table 1: Demographic Data of Respondents

\begin{tabular}{|c|c|c|c|c|c|c|c|}
\hline \multicolumn{2}{|c|}{ Educational Status } & \multicolumn{2}{|c|}{ Job Status } & \multicolumn{2}{|c|}{ Gender } & \multicolumn{2}{|c|}{ Period in Service } \\
\hline $\begin{array}{c}\text { Academic } \\
\text { Qualification }\end{array}$ & No of Resp. & Position & $\begin{array}{l}\text { No of } \\
\text { Resp. }\end{array}$ & Sex & $\begin{array}{l}\text { No of } \\
\text { Resp }\end{array}$ & $\begin{array}{l}\text { No of Yrs } \\
\text { in Org. }\end{array}$ & $\begin{array}{l}\text { No of } \\
\text { Resp. }\end{array}$ \\
\hline OND/A/L & $10(6)$ & Director/Dep Reg. & $23(10)$ & Male & $163(69)$ & $0-5$ & $54(23)$ \\
\hline HND/B.Sc/B.Ed & $69(29)$ & Deans & $18(8)$ & Female & $73(31)$ & $6-10$ & 63927) \\
\hline M.Sc/MBA/M.Ed & $62(26)$ & $\begin{array}{c}\text { Head of } \\
\text { Dept/University }\end{array}$ & $19(42)$ & & & $11-15$ & $78(33)$ \\
\hline $\mathrm{Ph} . \mathrm{D}$ & $97(41)$ & Admin Officers & $7(31)$ & & & & \\
\hline & & Principal Officers & $29(10)$ & & & & \\
\hline Others & - & & & & & $16 \&$ above & $41(17)$ \\
\hline
\end{tabular}

The table 1 above shows the demographic detail of the respondents for the study. From the data on educational background of the respondents, 8 of them have the OND certificate while the first degree has 69 respondents which also represent $29 \%$ of the respondent. For the-second degrees 62 of them which represent $26 \%$ have Masters degree. There were also 97(41\%) of them with Ph.D degrees. The educational background of 
all the respondents shows a good representation of personnel in the educational institutions. It shows strong academic qualification of the workforce.

In relation to job status of the personnel surveyed, 23(10\%) of them are directors Deputy Registrars. For Deans, 18 of them which represent $8 \%$ are in that category. In the case of department/unit heads, we had 99 of them which also represent $42 \%$ of the sample. Admin officers and principal officers that make up the sample were $72(31 \%)$ and $24(10 \%)$ respectively. This further shows that the appropriate personnel were those sampled for data generation for the study. As for gender, 163(69\%) of the respondents are males while 73 of them which represents $31 \%$ are females.

The period of stay in the institutions is also viewed as a factor that could enhance creation or belonging to networks within the institutions and using it as a means of reaching both individual and organizational goals. The data showed that 54(23\%) of the respondents have stayed between O-5yrs. Another 63(27\%) of them have been with their institution for 6-10yrs and the 11-15yrs ranged had 78(33\%) respondents. The 16yrs and above also have as much as $41(17 \%)$ respondents. From the response distribution on years of service, it is obvious that they have spent quality years in the institutions to have knowledge of existing groupings.

Table 3: Existing of Affiliations in the Institutions

\begin{tabular}{|l|c|c|}
\hline Responses & Respondents & \% of Responses \\
\hline Yes & 193 & 81.8 \\
\hline No & 21 & 8.9 \\
\hline Somewhat & 22 & 9.3 \\
\hline Total & 236 & 100 \\
\hline
\end{tabular}

Source: Survey Data, 2014

Table 3 shows details on whether group affiliations exist in the tertiary institutions. The results show that 193 of the respondents acknowledge the presence of group affiliation. This also represents $81.8 \%$ of the respondent sample. 21 and 22 of them responded to the "No" option and "Somewhat" option respectively. This also represents $8.9 \%$ and $9.3 \%$ response rate respectively. The response pattern clearly indicates that there are grouping within the tertiary institutions that are formed for the purpose of achieving common goals.

\subsection{Test of Hypotheses}

The hypotheses that were earlier stated in the study are analyzed in this section. The Spearman Rank (rho) statistic was used for the analysis.

$\mathrm{H}_{\mathrm{O} 1}$ : There is no significant relationship between religious affiliations and altruism

Table 4: Correlation result on the relationship between religious affiliations and altruism

\begin{tabular}{|l|l|l|r|r|}
\hline & & & $\begin{array}{r}\text { Religious } \\
\text { Affiliations }\end{array}$ & Altruism \\
\hline Spearman's rho & Religious Affiliations & Correlation Coefficient & 1,000 & $.670^{* * *}$ \\
\hline & & Sig.(2-tailed) &. & .000 \\
\hline & & $\mathrm{N}$ & 236 & 236 \\
\hline & Altruism & Correlation Coefficient & $.670^{* * *}$ & 1,000 \\
\hline & & Sig. (2-tailed) & .000 &. \\
\hline & & $\mathrm{N}$ & 236 & 236 \\
\hline
\end{tabular}

$* *$ Correlation is significant at the 0.01 level (2-tailed)

From the results shown in table 4 , the $\mathrm{r}$-value is 0.670 . This simply means that a positive relationship exists and is also shown to be significant with the p-value of 0.000 which is less than our 0.05 sig level in the 2 tailed test. This means that our stated null hypothesis is rejected. In other words, a significant relationship exists between religious affiliations and altruism.

$\mathrm{H}_{\mathrm{o} 4}$ : There is no Significant Relationship between membership of religious group and sportsmanship

Table 5: Correlation result on the relationship between religious affiliations and sportsmanship

\begin{tabular}{|l|l|l|r|r|}
\hline & & & $\begin{array}{r}\text { Religious } \\
\text { Affiliations }\end{array}$ & Sportsmanship \\
\hline Spearman's rho & Religious Affiliations & Correlation Coefficient & 1.000 & $.621^{* *}$ \\
\hline & & Sig.(2-tailed) &. & .000 \\
\hline & & N & 236 & 236 \\
\hline & Sportsmanship & Correlation Coefficient & $.621^{* *}$ & 1,000 \\
\hline & & Sig. (2-tailed) & .000 &. \\
\hline & & N & 236 & 236 \\
\hline
\end{tabular}

**Correlation is significant at the 0.01 level (2-tailed) 
The results of the analysis are as shown in table 5 above. From the results with $r=0.621$, it means that a positive relationship exist between the examined variables and the relationship is significant at a $\mathrm{p}=0.005$. From this result, we reject the null hypothesis. This means that a significant relationship exists between membership of religious affiliations and sportsmanship in the tertiary institutions studied.

\section{Discussion of Findings}

The results of the study show convincingly the existence of religious affiliations in organization that have common goals. The findings supports Melford (2000) view on informal networks in organization as groups mutually existing for their benefits therefore stay connected to each other. It exists based on trust, shared values and beliefs and shares together information that promotes social emotions amongst members of same group. Essentially the studied organizations have groups arising from the primary operationalized formation (religious affiliation) in the study which are also in tandem with literature. The religious grouping is therefore considered as dominant in work organizations (Ebeths, 2007).

Nowadays, tertiary institutions similar competition challenges like other service-oriented institutions like banks, telecommunication, education, insurance, etc., in areas of customer demanding for high quality services at competitive prices and delivered with courtesy and conscientiousness. Universities are peoplecentered, where emphases are on customer-oriented marketing (Chao-Chan, 2011). Hence, the knowledge service market favours the buyer, rather than the seller (Lee, Chen, Chen and Chen, 2010). With the growing competition and increasingly complex business environment there is reduction in the ability to understand and anticipate the environmental requirements of organizations and as a result, organizations can not precisely formulate their staff expectations to work, because the outstanding performance is not due to the common efforts of the staff, therefore, organizations need employees with a desire to move beyond formal job expectations (Morrison, 1994 as cited in Sahafi, et al, 2013). This concept has not find proper place in educational institutions (Sahafi, et al, 2013) despite the positive influence on knowledge brand image. The peculiarity and sensitivity of the health care delivery has increased the requirements of $O C B$. Tertiary institutions need to train and encourage their employees to discharge their duties professionally and put extra efforts $(O C B)$ where required.

Organ (1988) opined that $O C B$ are the various behaviour who are beneficial to the organization, but it is made spontaneously by members and never been directly or explicitly instructed in the organization formal reward system. Furthermore, $O C B$ is not within the role or the range provided by job description, such behaviour is more similar to personal choice. In the opinion of Izhar (2009) $O C B$ refers to "those organizationally beneficial behaviour and gestures that can neither be enforced on the basis of formal role obligations nor elicited by contractual guarantee of recompense." Since these extra ordinary efforts are optional their presence cannot be enforced (Organ, 1988), and their omission is not considered as punishable in the organizations (Van Dyne et al, 1995). Turnipseed and Rassuli (2005) mentioned the examples of these $O C B$ behaviour as understanding and cooperation with colleagues, mentoring, performing extra duties without delay and complaint, punctuality, volunteering, efficiently use of organizational resources, sharing ideas and positively representing the organization.

The findings from the hypotheses tested reveal that religious affiliation is significantly associated with organizational citizenship behaviour. This implies that understanding and cooperation with colleagues, mentoring, performing extra duties without delays and complaints, punctuality, volunteering, efficiently use of organizational resources, sharing ideas and positively representing the organization will increase service efficiency, students satisfaction, students revisit for higher degrees and recommendation to others, hence, quality knowledge and allied services delivery. Our results were consistent with the findings of other previous studies (Chi-Cheng et al 2011; Yaghoubi et al, 2011; Kpakol et al, 2016). Also, the positive casual relationship between religious affiliations and OCB measures of altruism and sportsmanship has shown clearly the leading role of networks toward enhancing community practices that will also enhance effective and efficient means towards reaching goals in tertiary institutions. The good perception of the of universities services which are developed by the attributes of groups such as caring, nice, friendly, responsiveness, etc. helps in attracting and building students and other stakeholders loyalty and re-visit intention, thus, achieving overall institutional goals.

\section{Conclusion}

In this study, religious affiliations and their influence on organizational citizenship behaviour was examined (Emego, 2003, Lipsey and Folan, 2007). Various groups no doubt have taken various forms of emergency but this study concerned itself with religious affiliations which according to Gina (2010) is one of the major informal relational networks in indigenous African organization which in this circumstance are the higher tertiary educational institution investigated. The study has raised some research questions and generated data. The analyzed data showed that religious affiliations grouping instigate high sense of citizenship behaviour among group members whose action are goal directed. The affiliation as created is the reason for good 
expression of altruism and sportsmanship as they show concern for one another. From the findings it was concluded that citizenship behaviour in organization can be triggered and sustained through deliberate creation of social institutional networks that strive toward achieving their common goals.

\section{References}

[1]. Ahiauzu, A. I. (1983) Cultural influences on managerial industrial relations policies: The case of Hausa and Ibo workplaces in Nigeria, Labour and Society 8(2): 30-40

[2]. Aldrich, H. E. and Pfeffer, J. (1979) Environments of organizations, Annual Review of Sociology, 2: 79 - 105.

[3]. Alotaibi, A.G (2012) Antecedent of organizational citizenship behaviour, A study of public personnel in Kuwait. Public Personnel Management, 30:363-76.

[4]. Appelbaum S.; Bartolomucci N.; Beaumier E.; Boulanger J.; Corrigan R. D. (2004) Organizational Citizenship behaviour: A case study of culture, leadership and trust. Management Decision 42:13-40.

[5]. Ashour, M. B. (1982) Organi.saion culture in the mining industry, Homewood, 111.: Dorsey Press.

[6]. Athenxa, X. and Mariam, S. (2002) Organizational Culture and Transformational Leadership as Predictors of Business Unit Performance, Journal of Managerial Psychology, 22(6),566-579.

[7]. Bandura, A. (1977) Social learning theory, Englewood Cliffs, New Jersey: Prentice-Hall.

[8]. Baridam, D.M. (2008), Research Methods in Administrative Science, Port Harcourt, Sher Brooke Associates.

[9]. Bies, R. J. (2011) Interactional (in) justice: The sacred and the profane. In: Greenberg, J. Cropanzano, R, (eds.) Advances in organizational Justice. Stanford CA: Stanford, CA: Stanford University Press.

[10]. Bowers, D. G. (1973) Work humanization in practice: what is business doing? In Heisler, W. J. and Houck, J. W. (eds.) A matter of dignity: inquiries into the humanization of work, Notre-Dame: University of Notre-Dame Press.

[11]. Campbell, D. and Dunnette, A. B. (1969) Early experience: myth and evidence, New York: Free Press of Glencoe.

[12]. Castro, C.B, Armario E, Ruiz D.M. (2004) The influence of employee organizational citizenship behaviour, customer loyalty, International Journal Service and Industrial Management 15:27-53.

[13]. Child, J. (1972) Organisational structures, environment and performance: the role of strategic choice, Sociology, 6: 1-22

[14]. Child, J. (1974) Organisation, management and adaptiveness, Working Paper, Birmingham: University of Aston.

[15]. Cronbach, L. J. \& Meahi, P. E. (1955) Construct validity in psychological tests.

[16]. Cumming, L. L. (1981) Organisational Behaviour, Annual Review of Psychology, 33: 54 1-579.

[17]. Deutsch, K. (1972) Social Mobilization and organisational development in Eckstein, H. and Apter, D. (eds.) Comparative Management New York: Free Press: 584-590.

[18]. Durkheim, N. (1912) Sociology of Politics, New York: Oxford University Press.

[19]. Edwards, W. (1962) Subjective Probabilities inferred from decisions, Psychologist Review, 69: 109-35.

[20]. Ejiofor, P. (1981) Management in Nigeria: theories and issues, Onitsha, Nigeria: African Educational Publishers.

[21]. Eturk, A. (2006) increasing organizational citizenship behaviour of Turkish academicians, Journal of Managerial Psychology 22:257-70.

[22]. Evans, M. G. (1970) The effect of supervisory behaviour and the path-goal relationship" Organisational Behaviour and Human Performance 5: 200-220.

[23]. Fielder, F. E. (1974) Leadership and management effectiveness, Glenview: Scott, Foresman and Company.

[24]. Freeman, J. (1982) The origins of the women's liberation movement, in Huber, 3. (ed.) Changing women in a changing society, Chicago: University of Chicago Press.

[25]. Hannan, E. and Freeman, C. T. (1977) Themes in organizational research, The Hague: Mouton

[26]. Hare, M. (1962) Labour emigration among the Mozambique Thonga: cultural and philosophical factors, Africa, Vol. 49, pp. 117122.

[27]. Harwarth, L.C and Lery E.P. (2007) The importance of instrumentality beliefs in the prediction of organizational citizenship/ behaviour, Journal of Broadcasting Behauiour 59:64-75.

[28]. Hickson, D. 3.; Hinnings, C. R.; Lee, C.A.; Schneck, R. E. and Pennings, J. M. (1971) A strategic contingencies theory of interorganisational power, Administrative Science Quarterly, 16: 216-229.

[29]. Homans, G. C. (1970) The functionalist theory of stratification: Two decades of controversy, in Tunim, M.M (ed.) Readings on social stratification, Englewood Cliffs, NJ: Prentice-Hall.

[30]. Horton, P. E. and Hunt, C. L. (1984) Sociology, New York: McGraw-Hill

[31]. House, R. J. (1974) The path-goal theory of leadership: some post-hoc and prior-test, Journal of Contemporary Business, 14: 43 1440.

[32]. Hunt, A. (1972) A survey model of organizational change, London: Aldine Press.

[33]. Kast, F. E. and Rosenzweig J. E. (1982) Organisations and management: A systems and contingency approach, Toyo: McGrawHill.

[34]. Katz, D. and Kahn R. L. (1978) The social psychology of organization: New York: John Wiley and Sons.

[35]. Kenneth, L.G.E (1965) Power and Privilege: A theory of social stratification, New York: McGraw-Hill.

[36]. Kidder, L.P. (2012) The influence cofounder on the performance of organizational citizenship behaviour. Journal of Management, 28:29-648

[37]. Kuhn, J. W. (1970) Bargaining in grievance settlement, Columbia: Columbia University Press.

[38]. Laschinger, H.K. (2004) Hospital nurses perception of respect and organizational justice. Journal of Nursing Administration; 34:354.

[39]. Lawrence, P. R. and Lorsch V. (1967) Road belong to cargo, New York: McGraw-Hill.

[40]. Lee, C.R, \& Koh J.T. (2000). Predictors and Outcomes of Openness to Changes in a Reorganizing Workplace. Journal of Applied Psychology. 85. 132-142.

[41]. Lemons, .M (2010) Procedural justice in promotion decision: Using Perception of fairness to build employee commitment. Journal of Management Psychology, 16:268-80.

[42]. Lesile, J. H. (1982) Theory of Cultural change: the methodology of muitilinear evolution, Urbana, Illinois: University of Illinois Press.

[43]. Lind, E.A. and Tyler T.R. (2008) The Social Psychology Of Procedural Justice. New York: Plenum.

[44]. March, J. G. and Simon, H. A. (1976) Organisations, New York: Wiley.

[45]. Mitchell, B. L. (1979) Symbols, Signals and noise in organizational communication, New York: Wiley. 
[46]. Naami, A. (2005) A Study between organizational justice and lead occupational in industrial organization in Ahvaz. Psychology Journal; 13:79-92

[47]. Nachimias, C.F and Nachimas, D (1996) Research methods in the social sciences, Fifth edition. St Matins press incorporation London, UK.

[48]. Organ, D.W. (1998) Organizational citizenship behaviour: The good soldier syndrome Lexington, M.A: Lexington books.

[49]. Otite, O. and Ogionwo, p. (1979) The study of social thought in Africa, in Otite. 0. (ed.) Themes in African social and political though, Enugu, Nigeria: Fourth Dimension Publishers.

[50]. Pfeffer, J. (1981) Some consequences of organizational demography: potential impacts of an aging workforce in Oppenheimer V. K. (eds.) Aging: Social Change, New York: Academic Press.

[51]. Pfeffer, J. and Salancik, G.R. (1978) The external control of organizations: A resource dependence perspective, New York: Harper and Row.

[52]. Podsadoff, T. (1982) Modelling effects, Public Opinion Quarterly, 87: 452-468.

[53]. Porter, L. W. and Lawler, E. E. (1968) Properties of organization structure in relation to job attitude and job behavior, Psychological Bulletin, 64: 23-51.

[54]. Salancik, G. R. and Pfeffer (1977a) Field Stimulations for organizational behavior research, Administrative Science Quarterly, 24: 638-649.

[55]. Sheriff, P. E. and Sheriff R. (1972) Unrepresentative bureaucracy, Sociology, 8 (9): 125 - 137.

[56]. Steiner, O. A. (1968) Forms of formal organization, New York: McGraw-Hill Book Co.

[57]. Tavakoli, Z. (2007). Study of education of organizational citenzenship behaviour on job Commitment in cultural recreational organization of municipality (MS Dissertation) Faculty of psychology \& Educational, Isfahan University.

[58]. Thompson, .S. (2001) The Effect of perceived justice on satisfaction and behaviour intensions: The Case of Computer Purchase. Journal of Distribution Management.29: 109-24.

[59]. Trimble, A. (1974) Workers' Attitudes of technical change, Paris: OECD.

[60]. Wat, P. and Shaffer A.M. (2007) Equity and relationship quality in fluency on organizational citizenship behaviour, Personal Review, 34:406-22.

[61]. Yaghoubi, M, Raeisi A.R, Afshar M, Yarmohammadian M.H. (2010), The relationship between the learning organization and organizational commitment among nursing managers in educational hospital of Isfahan University of Medical sciences in Iran. Journal of Nursing and Midwifery Research. 15:78-84.

[62]. Yilmaz, K. (2009) Organizational citizenship and organizational justice in Turkish primary schools, Journal of Educational Administration; 47:108-26.

[63]. Okpu. T. \& Kpakol A.G (2015). Managing employee trust perceptions for sustained workplace harmony in the Nigerian banking industry. International Journal of Managerial Studies and Research, 3(5): 65 - 73

[64]. Kpakol, A.G., Obiora, J.N \& Jaja, S.A (2016). Employee participation and organizational identification: Implications of the mediating effect of organizational culture. European Journal of Business and Management, 8(11) 32 - 44 